Article

\title{
Ecotourism versus Mass Tourism. A Comparison of Environmental Impacts Based on Ecological Footprint Analysis
}

\author{
Mehdi Marzouki ${ }^{1, *}$, Géraldine Froger ${ }^{2}$ and Jérôme Ballet ${ }^{2}$ \\ 1 Local government (Yvelines department), 2 place Pierre Bonnard, Guyancourt 78280, France \\ 2 CEMOTEV-UVSQ (EA 4457), 47 boulevard Vauban, Guyancourt 78280, France; \\ E-Mails: geraldine.froger@uvsq.fr (G.F.); jballetfr@yahoo.fr (J.B.) \\ * Author to whom correspondence should be addressed; E-Mail: mehdi.marzouki@wanadoo.fr; \\ Tel.: +33-139-255-700.
}

Received: 11 October 2011; in revised form: 12 December 2011 / Accepted: 14 December 2011 / Published: 10 January 2012

\begin{abstract}
Academic and policy interest in ecological footprint analysis has grown rapidly in recent years. To date, however, the application of ecological footprint analysis to tourism has been limited. This article aims to discuss the potential of ecological footprint analysis to assess sustainability in tourism. It is about a comparison of the global environmental impacts of different forms of tourism in southern countries where tourism is a major source of foreign exchange earnings. It illustrates how an ecotourism destination has a larger ecological footprint than a "mass" tourism destination.
\end{abstract}

Keywords: ecological footprint; sustainable tourism; environmental impacts; global scale; Tunisia; Seychelles

\section{Introduction}

The ecological footprint (EF) concept was introduced in the 1990s by William Rees and Mathis Wackernagel $[1,2]$. The concept is rooted in the search for indicators of sustainable development and more in particular the wish to measure how the human appropriation of the earth's resources relates to the carrying capacity of the earth. The aggregated use of land is seen as a good common denominator to express the impact of humans on the earth's natural resources.

The EF measures the amount of biologically productive land and sea area an individual, a region, a given population or a human activity requires to produce all the resources it consumes and to absorb 
the corresponding emissions (such as carbon dioxide from fossil use), using prevailing technology and resource management practices. It compares this measurement to how much land and sea area is available [3-5]. The EF is usually measured in global hectares. Biologically productive land and sea includes area that (1) supports human demand for food, fibre, timber, energy and space for infrastructure and (2) absorbs the carbon dioxide emissions from the human economy.

The total EF of an individual or a given community is broken down into a number of components. Often six components are distinguished [6-9]: use of arable land (for food, feed and other agricultural products), use of pasture land (for animal grazing), use of forest/woodland (for timber), use of built-up space (for living, etc.), use of productive sea space (for fish), and use of forest land to absorb $\mathrm{CO}_{2}$ that was emitted due to human activities. Ecological footprint analysis (EFA) aims at expressing demand for all impact components as an equivalent, imaginary land area (global hectares or gha) $[8,10]$.

According to [4] (p. 1964), "the EF deviates from other sustainability indicators in two respects: it expresses the impacts of humanity on the environment in one common unit (use of bioproductive space) and it can be related to the carrying capacity of the earth (the available bioproductive space or so-called "biocapacity")".

Many potential applications of EFA have been proposed e.g., [11]. To date, however, the application of EFA to tourism has been limited. EFA can be used in the tourism sector to calculate the biological demands of this activity [12]. This is a pertinent measure because it takes into account the impact of air travel and the areas of land used to cater for the various types of tourism-related consumption. The question of travel and transport is likely to call into question some types of tourism intended to be sustainable, such as ecotourism, particularly when they take place in destinations that are remote from the home country of the tourists [13]. For example, ecotourists generally originate from developed countries and frequently holiday in less developed countries in the South. Potential beneficial environmental impacts of ecotourism at the local level (in the sense that it puts a minimum threat on local ecosystems through the conversion of lands, trampling, collection of species, etc.) may be outweighed by harmful effects at the global scale (air travel).

This article then seeks to discuss EFA as a tool to assess sustainability in tourism. Our analysis reports a case study concerning the application of the EFA to Tunisia, which is often qualified as a "mass tourism" destination [14]. Our objective is to compare our findings with those reported by Gössling et al. [15] for the Seychelles. According to Gössling et al. [15] (pp. 206-207), "The development of travel mirrors a process of increasing competition between destinations, and can also be seen as an indicator of the growing inter-changeability of destinations. Particularly destinations in the tropics become replaceable because sun-sand-sea travel choices are increasingly made on the basis of two factors only: travel (flight) duration and hotel standard. Considering these trends, the Seychelles are unique in their effort to not become a mass-tourism destination and to attract the high-value segment of international tourism". Tourism is the second major source of foreign exchange earnings for the Seychelles, and a pristine environment is understood as the precondition for attracting an exclusive, wealthy clientele [16]. The Seychelles have safeguarded a wide range of ecosystems in protected areas, which are ultimately dependent for their existence on financial resources derived from tourism. They have based their marketing on the image of a pristine, exclusive eco-destination that seriously attempts to integrate environmental conservation and development $[17,18]$. 
Using EFA to assess sustainability of tourism in these two southern destinations is interesting because it focuses on the environmental impacts of tourism scenarios not on a local scale [19,20] but on a more global scale. It takes into account the global environmental aspects of travel. It illustrates that a destination branding itself as ecotourism destination has a larger EF than a "mass" tourism destination. Section 2 clarifies the method of calculating the EF applied to tourism. Section 3 compares the EF of tourism between Tunisia and Seychelles. Section 4 discusses the potential and limitations of the EFA and its outcome.

\section{Methods}

EF aims at expressing - using space equivalents - the appropriation of biologically productive area by individuals or nations. The idea of the concept is to compare the area required to support a certain lifestyle with the area available, thus offering an instrument to assess if consumption is ecologically sustainable [3,21]. The method used for our EFA applied to several forms of tourism is based on a reference model developed by Gössling et al. [15]. This method consists of several steps, each of which yields one of the components of the total EF. Generally, the method remains the same for studies that have applied the EFA to the tourism sector [5]. It relates human consumption and waste production to six major components of productive space: built-up land (that refers to spaces where the biological productivity isn't used because these areas have been covered with human artefacts such as buildings and roads), fossil energy land (that corresponds to the area of newly planted forest in order to store the carbon dioxide released in the atmosphere by human activities, that represents the footprint of different fossil energy sources), arable land, pasture, sea space, and forest [22,23]. Furthermore, these different components are assigned to four different sectors: "transport", "accommodation", "leisure activities" and "food and fibre consumption".

Firstly, "transport" comprises all travel related to the vacation, including travel to/from airports, return-flights, and all travel at the destination. The corresponding EF needs to consider both energy and infrastructure components. It consists of two parts: on the one hand the areas of land that are built on to provide infrastructures for roads, railways, parking sites, ports and airports, and on the other hand, the areas required for the absorption of carbon and the production of hydrocarbons. The areas related to the absorption of carbon and hydrocarbon production are calculated taking into account air travel and other modes of transportation. The method of calculation is the same, except that the space required for air travel is weighted by a factor of 2.7 [15]. This space is calculated on the basis of the mean number of kilometres per head for the different types of transport. Once this value has been obtained, it must be converted into gigajoules by means of a conversion factor designated $\alpha$ ( $\alpha_{1}$ for air, and $\alpha_{2}$ for road), and then converted into an area using another conversion factor, designated $\beta$ [15]. The area occupied by infrastructures corresponds to the area required for development linked to transportation for tourists. The calculation is based on the built-on area of the facilities, and the total number of tourist arrivals for each of them. The area required per tourist thus obtained expresses the number of hectares per head for transport-related infrastructures. This result must be adjusted to take into account the proportion of tourists amongst the total of incoming passengers (tourists and other passengers), i.e., a correction via the tourists/total passengers ratio. 
Secondly, as for "accommodation", the tourist footprint consists of the area required for rooms/apartments, and the fossil energy land to account for energy use (including mainly heating/cooling, air conditioning, cooking, illumination). The methods used to calculate these two factors (infrastructure and energy components) are fairly similar, but they differ with regard to the data that must be included. The surface area required to accommodate the tourists is calculated on the basis of the capacities in terms of beds available per category of accommodation. A mean surface area per person is thus obtained. The energy required per tourist is calculated in a way fairly similar to that described in the previous paragraph. The main difference lies in the fact that the calculation is no longer based on capacities, but on actual overnight stays. The quantities of energy in megajoules per head and per category of accommodation are used here to calculate the mean value of the quantity of energy consumed per overnight stay. This mean value is then multiplied by the mean duration of tourist stays, and then in the same way as for air transport, it is converted into a surface area using a new conversion factor, designated $\mu$.

Thirdly, "leisure activities" include the visitation of specific locations for recreational purposes and may be divided into attractions (museums, etc.) entertainment (cinema, shopping, etc.) and sport activities (diving, golf, etc.) The area required for leisure spaces has been considered by Gössling et al. [15] to be negligible, with the exception of golf courses, which correspond to a significant proportion of the land area used by the tourists. Consequently, the calculation is carried out using the following ratio: golf areas/total number of tourists.

Finally, "food and fibre consumption" assesses the footprint of food and fibre, based on arable land, sea space, forest and pasture. Due to the poor official statistical database, it is assumed that the quality and quantity of the food and fibres consumed at the destination is similar to consumption at home. It is therefore necessary to isolate the consumptions of groups of tourists on the basis of their geographical origins, and then to revise these figures in relation to the length of tourist stays. This calculation can in fact be summarized as that of the mean consumption for the four components on the basis of the number of tourists and of where they come from. The area required for tourist consumption is indexed on the basis of the WWF report [24].

Figure 1 illustrates our approach to the construction of an EF applied to tourism.

The term ecological footprint is designated EF, and the various different components of the indicator are designated $\mathrm{EF}_{\mathrm{i}}$, where $i$ ranges from 1 to 9 .

In order to aggregate the different categories of space to a total footprint, the areas (built-up land, fossil energy land, arable land, pasture, sea space, and forest) are multiplied by "equivalence factors" [25]. Theses factors inform about the area's relative productivity (measured in primary or green biomass productivity) as compared to world-average space, which is given the equivalence factor of 1 . In 2004, built-up land is, for example, 2.64 times more biologically productive than world-average space, and is therefore multiplied with factor 2.64. These equivalence factors are calculated every year and are identical for every country in a given year. They translate the area supplied or demanded of a specific land use type (i.e., world average cropland, grazing land, etc.) into units of world average biologically productive area (global hectares - gha) and varies by land use type and year. The equivalence factors for each category of space, based on the Living Planet Report [24] and resumed by Gössling et al. [15], as well as those based on Ewing et al. [10] are shown in Table 1. 
Figure 1. EF of tourism.

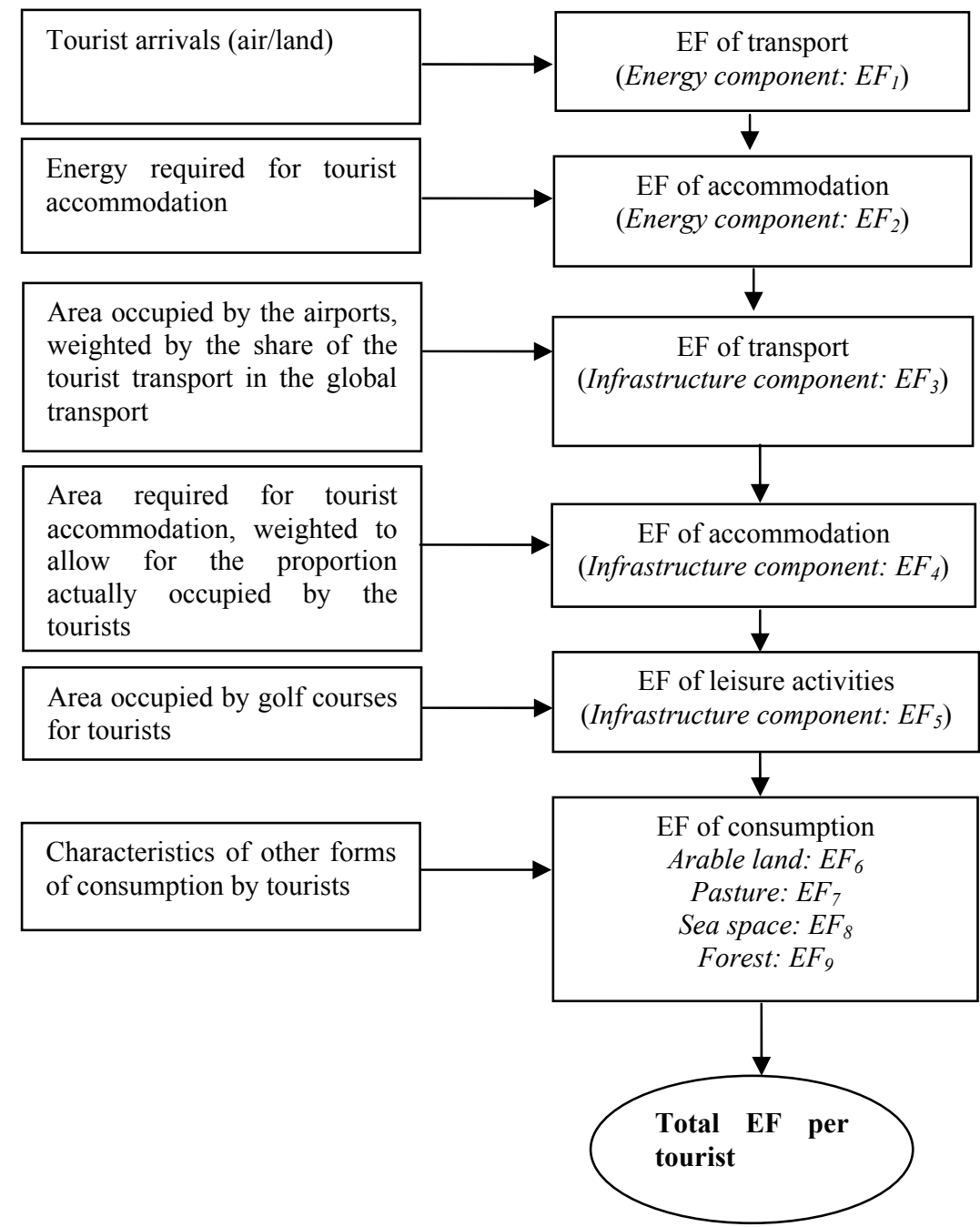

Table 1. Equivalence factors (based on relative biomass yield), Source: [15].

\begin{tabular}{lc}
\hline Area type & $\begin{array}{c}\text { ef } \\
\text { per hectare) 2000 }\end{array}$ \\
\hline Fossil energy land (newly planted forest area needed to absorb & 1.8 \\
emitted $\mathrm{CO}_{2}\left(\mathrm{ef}_{1}\right)$ & 3.2 \\
Built-up land (required for roads, buildings, etc.) $\left(\mathrm{ef}_{2}\right)$ & 3.2 \\
Arable land (for growing crops) $\left(\mathrm{ef}_{3}\right)$ & 0.4 \\
Pasture (for grazing animals) $\left(\mathrm{ef}_{4}\right)$ & 0.1 \\
Sea space (for harvesting fish and other sea food) $\left(\mathrm{ef}_{5}\right)$ & 1.8 \\
Forest area (for producing wood for furniture, paper, etc.) $\left(\mathrm{ef}_{6}\right)$ & \\
\hline
\end{tabular}

In this way, the EF is calculated for the areas $\left(E F_{i}\right)$, and the predetermined equivalence factors $\left(e f_{j}\right)$ for every year on the basis of the equation below:

$$
E F=\sum_{k=1}^{2} E F_{k} \cdot e f_{1}+\sum_{m=3}^{5} E F_{m} \cdot e f_{2}+\sum_{n=6}^{9} E F_{n} . e f_{n-3}
$$

For the components associated with fossil energy, $d_{a}$ and $d_{v}$ designate the mean distances travelled per tourist by air and by road, and $\mathrm{e}_{\mathrm{ni}}$ the mean energy consumed per tourist for accommodation. For 
the components associated with infrastructures and leisure activities, $\mathrm{s}_{\mathrm{t}}, \mathrm{s}_{\mathrm{h}}$, and $\mathrm{s}_{\mathrm{g}}$ are reported, corresponding to the mean surface areas per tourist required for travel, accommodation, and golf courses and other leisure activities respectively. $\delta$ and $\eta$ are respectively the fraction corresponding to the tourism-related use of the transportation infrastructures and occupation of accommodation. Finally, $c_{a}, c_{p}, c_{e}$, and $c_{f}$ designate the mean relative consumption in hectares per tourist in terms of arable land, pasture, sea space, and forest. The footprint can then be expressed as follows:

$$
E F=e f_{1} \cdot\left[\beta \cdot\left(d_{a} \cdot \alpha_{1}+d_{v} \cdot \alpha_{2}\right)+e_{n i} \cdot \mu\right]+e f_{2} \cdot\left(s_{t} \cdot \delta+s_{h} \cdot \eta+s_{g}\right)+e f_{3} \cdot c_{a}+e f_{4} \cdot c_{p}+e f_{5} \cdot c_{e}+e f_{6} \cdot c_{f}
$$

The EF describes to what degree tourism remains within the scope of the environment's ability to regenerate, and reveals the distribution of the pressure brought to bear on the environment as a function of the type of consumption [10].

Previously, the preferred index used to analyse the environmental impact of tourism was usually the carrying capacity of the earth [21]. Moreover, during the last ten years many sustainability indicators have been proposed and discussed [26]. Nevertheless, all of these indicators are indicators of environmental impact at the local level, and the advantage of the EFA is to provide an indicator of sustainability at the global level by taking air travel into account [27-29]. As a result, a tourist's footprint will include a wider range of impacts than most of the other indicators currently applied to the environment (at the local level but also at the global level with the carbon footprint which takes only carbon issue into account). Our approach will then compare tourism in Tunisia and the Seychelles with regard to their EF. Tunisia and the Seychelles have been chosen as study cases because tourism is a major source of foreign exchange earnings in both cases and each destination corresponds to a different kind of tourism: the Seychelles seek to brand themselves as an ecotourism destination, while a large part of some coastal areas of Tunisia can be considered as mass tourism.

\section{Results}

For the Seychelles, the study carried out by Gössling et al. [15] provides some very detailed data about the country's EF. No such information is available for Tunisia in any paper. We therefore propose to calculate the ecological footprint of tourism in Tunisia by using the data of the ONTT report of 2004 [30] and using some parameters and coefficients introduce in the article of Gössling et al. [15], to compare our results with those reported in this paper for the Seychelles in 2000.

The use of data for 2004 for the Tunisian case is not problematic because of the stability of the inputs required by the EFA (origin of tourists, categories of accommodation establishments, airports and golf courses) between these two years. The quantitative data such as tourist arrivals and length of stay (5.1 days for 2004 [30]) have few consequences for the footprint calculation because the output is a mean value. Nevertheless, different hypotheses were required due to the limited availability of data.

We first formulated two hypotheses for the energy component linked to transport. The first concerns the distances to be taken into account. So far these have tended to be homogenized, and refer solely to the locations of the capital cities of the countries of origin of the tourists (see Appendix 1).We then refer to the details of kilometres on the airline website. The second hypothesis concerns road travel by tourists once they have arrived at their destination, which we have assumed to have a mean value of the order of $300 \mathrm{~km}$ [30]. This value is assumed as a mean of the tourism trip in Tunisia where 
the primary motivation of the tourists (about $80 \%$ ) is sea-sand-sun with few trips, and the others $20 \%$ of tourists having more trips with desert excursions in the South for example or other forms of excursion in the North.

Secondly, for the infrastructure component linked to means of transportation, we also formulated some new hypotheses. As the two most significant means of transportation are air and road, we focussed our calculations solely on these two types of travel. Maritime transport has been left out of the equation due to the tiny fraction this means of locomotion for tourists represents for tourists visiting Tunisia (less than 3\% of the tourism transport referring to ONTT data). Furthermore, since the roads also carry heavy traffic unrelated to tourism, the area occupied per tourist for this type of construction has also been ignored. Thus, the area related to the share of building for transport is in fact focussed on the areas occupied by the airports (see Appendix 2).

Thirdly, for the infrastructure and energy components related to accommodation, we have adopted several hypotheses to offset the lack of data. The first concerns the theoretical data for the different parts of the calculation. The area per capita has been taken from article [15], with a few modifications. As this study was carried out in the Seychelles, where we assumed that the space required per tourist was greater than that required per tourist in Tunisia because of the concentration of tourists in the accommodation establishments which is the major characteristic of a mass tourism destination (see Appendix 3), so we assumed that it was necessary to reduce this theoretical space considerably. We have considered $50 \%$ of the space required per tourist in the Seychelles. Energy consumption was taken to be the same for both of these tourism zones. As a result, the data provided by Gössling et al. [15] were also used to construct this aspect of the EFA applied to Tunisia, but we adjusted the parameters used for the Seychelles by considering that energy consumption is the same for each category of accommodation establishments (about $80 \mathrm{MJ}$ per bed night) because the distinction between categories in Tunisia refers essentially to the quality of services proposed.

Finally, the data for the leisure activities and consumption were also lacking, so once again we had to adopt several hypotheses. There are only a few golf courses in Tunisia, and they are assumed to occupy a mean area of 90 ha as in the case of the Seychelles. We also adopted hypotheses related to consumption to assess footprint of food and fibres and to overcome the poor official statistical database and the unwillingness of the tourist industry to provide data. First, it was assumed that the quality and quantity of the food and fibre consumed at the destination is similar to consumption at home. Evidence suggests that there is at least some similarity [31]. We assumed that the consumption of tourists during their stay in Tunisia would be similar to consumption in their home country [32,33] (this hypothesis has been also made by Gössling et al. [15]). The second hypothesis concerns the uniformity of consumption by tourists from a given country of origin. In other words, the fact that there can be substantial differences between tourists coming from the same country is ignored in order to simplify the calculation. Moreover, the sensitivity of the coefficients for the assessment of uncertainty has not been ignored because the analysis conducted is done ex post. Thirdly, we take into account $85 \%$ of the tourist arrivals and as Gössling et al. [15] it was assumed that for the 15\% remaining tourists the consumption corresponds to the average consumption of the others.

Some others coefficients were used to calculate the mean footprint of a tourist for a trip in Tunisia. We used those detailed in the methodology of Gössling et al. [15] for the calculation of fossil energy land. It refers to the coefficient described before: $\beta(2.0), \alpha_{1}(0.04), \alpha_{2}(0.014)$ and $\mu(0.03)$. 
On the basis of these hypotheses and using the data of the ONTTT, we obtained the following results (Table 2).

Table 2. Calculation of the ecological footprint per tourist per stay in Tunisia.

\begin{tabular}{cccc}
\hline \multicolumn{2}{c}{$\boldsymbol{E F}$ component in ha } & Corrected $\boldsymbol{E} \boldsymbol{F}$ component in gha \\
\hline$\beta . \alpha_{1} \cdot d_{a}$ & 0.2500 & $e f_{1} \cdot \beta \cdot \alpha_{1} \cdot d_{a}$ & 0.4501 \\
$\beta . \alpha_{2} \cdot d_{v}$ & 0.0084 & $e f_{1} \cdot \beta \cdot \alpha_{2} \cdot d_{v}$ & 0.0151 \\
$\mu . e_{n i}$ & 0.0114 & $e f_{1} \cdot \mu \cdot e_{n i}$ & 0.0206 \\
$\delta . s_{t}$ & 0.0007 & $e f_{2} \cdot \delta \cdot s_{t}$ & 0.0022 \\
$\eta \cdot s_{h}$ & 0.0014 & $e f_{2} \cdot \eta \cdot s_{h}$ & 0.0046 \\
$s_{g}$ & 0.0002 & $e f_{2} \cdot s_{g}$ & 0.0007 \\
$c_{a}$ & 0.005 & $e f_{3 .} \cdot c_{a}$ & 0.0161 \\
$c_{p}$ & 0.0297 & $e f_{4} \cdot c_{p}$ & 0.0119 \\
$c_{e}$ & 0.0105 & $e f_{5} \cdot c_{e}$ & 0.0010 \\
$c_{f}$ & 0.0036 & $e f_{6} \cdot c_{f}$ & 0.0064 \\
\hline Ecological footprint per stay and per tourist & 0.5286 \\
\hline
\end{tabular}

This table presents the details of the calculation of the EF by referring to the mathematical expression expressed before. Thus, the mean EF of a tourist staying in Tunisia is of the order of 0.53 gha $[34,35]$ (by considering that a mean stay in Tunisia is 5.1 days according to the ONTT [30]). Transportation has the greatest impact, accounting for something of the order of $86 \%$ of the footprint. It should also be noted that the components associated with energy and infrastructures make the greatest contributions to the EF, accounting for nearly $90 \%$ of the total footprint.

A comparison of the situations in Tunisia and the Seychelles led us to use the results reported by Gössling et al. [15] for the Seychelles alongside the data reported above. The Table 3 below summarises these comparisons (For more details see Appendix 1, 2 and 3).

Table 3. EFA of tourism in Tunisia and in the Seychelles (adapted from [15]) in gha.

\begin{tabular}{lcc}
\hline Surface area & Seychelles & Tunisia \\
\hline Fossil energy land & 1.7373 & 0.4857 \\
Built up land & 0.0105 & 0.0075 \\
Arable land & 0.0632 & 0.0161 \\
Pasture & 0.0277 & 0.0119 \\
Sea space & 0.0032 & 0.0010 \\
Forest & 0.0145 & 0.0064 \\
Aggregated footprint per tourist & 1.8564 & 0.5286 \\
Aggregated footprint of all tourists & 218,482 & 1843,039 \\
\hline
\end{tabular}

This table presents the components of the EF of Tunisia and of the Seychelles. First of all, the surface areas are higher for all the components in the case of the Seychelles than in the Tunisian case. Fossil energy land for the Tunisian case represents less than $30 \%$ of fossil energy land required for the Seychelles due to the air travel. Conversely, the difference between the built-up land components (land directly used for tourist infrastructure) for both destinations is not so high, because infrastructure required for air transport is similar, only the accommodation has an incidence with a higher surface for 
the Seychelles. In the two case studies, built-up land is small because roads, airports, accommodation establishments, etc. are used by a great number of tourists per year, leading to a rather small per capita built-up area demand. The consumption for pasture and forest for Tunisia corresponds to $40 \%-50 \%$ of the consumption of the Seychelles for the reason that the length of stay here (10.4 days) is doubly more important than for the Tunisian case (5.1 days). Arable land and sea space for the northern destination considered refer to $25 \%-30 \%$ of the consumption for the southern country studied. This percentage is explained by the length of stay and the origin of the tourists with an important share of tourists coming from Eastern Europe which consume less than those from Western Europe.

Thus, the aggregated footprint per tourist is better for a tourist in Tunisia. Nevertheless, this conclusion is not valid when considering the aggregated footprint of all tourists for the two destinations, because the number of tourists in Tunisia is much higher in this country than in the Seychelles. So, comparison of the findings for Tunisia (with a footprint of the order of 0.53 gha per tourist for a length of stay of 5.1 days) and those for the Seychelles (with a footprint of the order of 1.85 gha per tourist for a length of stay of 10.4 days), confirms the extent to which air travel forms a substantial part of the EF of tourists. The shorter the distance tourists travel, the less pressure is brought to bear on the environment at the global level. Furthermore, some of the forms of consumption linked to food, which are expressed by the last four components, also reveal a definite advantage for Tunisia, which draws most of its tourists from Eastern Europe; these tourists consume less than those from Western Europe.

On the basis of this EFA, we can conclude that a tourist journey in Tunisia has a less harmful impact on the environment at the global level than a tourist journey in the Seychelles. Nevertheless, the aggregated EF per year for all categories of tourists combined is clearly lower for the Seychelles than for Tunisia due to the scale effect that results from the huge volume of tourists holidaying in Tunisia. The volume of tourists going to Tunisia is at least 30 times greater than that visiting the Seychelles (for the baseline years chosen for the two countries). In this way, the aggregated EF for the Seychelles corresponds to $12 \%$ of the total aggregated footprint for Tunisia, whereas the arrivals in the Seychelles represent only $3 \%$ of the total tourism arrivals in Tunisia.

\section{Discussion}

\subsection{Discussion of the Methodology Underlying the EF Applied to Tourism}

Of course EFA presents some boundaries [23,36]. First, EF is a stock indicator generally used to evaluate the sustainability of production or consumption of groups or areas. It leaves aside exchanges between areas. However, considering distribution between geographical spaces is necessary for the elaboration of a sustainability indicator [37]. Second, EF is a static measure and comparisons from time to time are not sufficient to understand changes. In particular, they cannot permit dissociation between substitution effects of goods or production processes that have been realised and decreasing or increasing effects in production or consumption. In articles [38,39], their point of view, underlined the necessity to develop a dynamic approach which can highlight stakes of different scenarios. Third, EF ignores technological changes, in particular, the development of clean technologies. Fourth, EF does not take into account freshwater withdrawals [40-42]. EF does not consider the freshwater consumed by tourists or the freshwater used by the tourism sector, whereas tourism does not have a neutral effect 
on freshwater resources at the local scale in arid countries like Tunisia or in islands like the Seychelles. The focus on fresh water and not water in general is important because fresh water is scarce. The water footprint (WF) was introduced in the field of water studies in 2002 [43] in order to measure the human appropriation of the globe's freshwater resources $[44,45]$. The term was chosen by analogy with the EF concept, but the WF concept has other roots than the EF concept. As a result, the methods to quantify the different indicators show both striking similarities and differences [46]. Results obtained by WWF [47] with the concept of WF shows that in Tunisia the stress on water resources could reach around $60 \%$ for freshwater withdrawn (from water bodies that are used and not returned), which corresponds to a severe stress, whereas stress on freshwater withdrawn is under $40 \%$ for the most part of the country. The situation is also problematic in the case of the Seychelles because of the high population density induced by tourism.

Nevertheless, EF presents advantages. As Moffatt [48] underlined, it possesses the capacity to give a clear message without ambiguity which can be used by public and policy makers and it is a key point of every good indicator.

Furthermore, as we apply it in the case of tourism, EF is not really concerned by previous critics. On one hand, we do not try to evaluate the evolution of tourism EF, but to compare, at any moment of time, the EF of two forms of tourism. On the other hand, we do not consider technological changes. They are short term. Finally, the distribution between two areas is taken into account in our evaluation by the travel of tourists between the departure area and the arrival area of tourists. In other words, we do not seek to use EF more than it can be used. Of previous boundaries, the only one that remains is the concern for freshwater withdrawals, and it is a true limit of our evaluation. On this point rests a crucial problem for evaluating tourism impact. However in the mean time, it is mainly a local stake and not a global one, which we are trying precisely to evaluate. We have nevertheless discussed this question in our conclusion.

For a decade, numerous sustainable indicators have been proposed and discussed (see for instance $[49,50]$, for a survey of main indicators by countries). Tourism did not escape from this freneticityy of sustainable indicators. As Ceron and Dubois [51] pointed out, most of these indicators are environmental indicators at a local level. Even if recent indicators are indicators that can be used for comparison between countries and are holistic indicators (see for instance [52-54]) they remain indicators about the impact of tourism in countries, while not considering travelling between countries. Now, Hunter and Shaw [27] underlines that an undeniable advantage of EF is to give a global indicator of sustainability. In this sense, it is not only an indicator of tourism in a place-country, but an indicator of tourism travelling from one country to another.

However, for a few years, another indicator has competed with EF called carbon footprint. Carbon footprint evaluates carbon emissions from production or consumption activities. Carbon footprint should be restricted to analyses that include only carbon emissions, in practice analyses proceed by including non carbon emissions, then using an equivalent indicator [55]. Carbon footprint is very similar to the Global warming potential (GWP) indicator used in life cycle assessment. Its success is indeed based on its readability concerning the effect of goods consumed on global warming [56].

Whereas carbon footprint measures $\mathrm{CO}_{2}$ emissions, EF measures the ratio between $\mathrm{CO}_{2}$ emissions and the biosphere capacity to keep carbon locked up, notably through forests. Some underline (for 
instance [57]) that, since $\mathrm{CO}_{2}$ emissions play a major role in $\mathrm{EF}$, it could be judicious to refer only to carbon footprint. It highlights policy stake, i.e., to reduce $\mathrm{CO}_{2}$ emissions.

Meanwhile, such a point of view seems excessive for two reasons. First, if global warming is a crucial stake, it is not due to $\mathrm{CO}_{2}$ emissions, but to the incapacity of the planet to absorb them. It is then more logical, even if less clear politically, to use EF. Second, the use of carbon footprint could lead to solutions with disputable effects on environment. For example, the development of biofuel is from a carbon footprint a good solution; $\mathrm{CO}_{2}$ emissions are reduced. But such a conclusion leaves aside the fact that the production of biofuel needs large areas which increase significantly the pressure on forests. EF, comparing emissions and capacity of absorption lead to a more mitigated conclusion. If areas needed to product biofuels contribute significantly in reducing forest which absorbs carbon, then biofuels are no more a good solution.

From a general perspective, the major asset of EF is to give an equivalent surface. This equivalent surface is furthermore a relevant indicator in the case of tourism, to an extent touristic activities are done on a given space and cannot be reduced to carbon emissions, even if, as we have noted in previous sections, it is of course a main dimension. EFA thus assesses environmental sustainability of tourism at a global level.

\subsection{Discussion of the Results Obtained for the Seychelles and Tunisia}

Applying the concept of the EFA to tourism makes it possible to determine the pressure that tourist consumption exerts on the area of productive land. It is measured in surface area (gha per tourist). It is an indicator that can be used to determine the sustainability of the different forms of consumption of tourism by considering the area required to cater for tourists' consumption relative to that naturally available. An average tourist's journey to the Seychelles requires more than 1.8 gha of world average space to maintain the necessary resource flows and to offset the contribution of greenhouse gas emissions to global warming. On the contrary, an average tourist's journey to Tunisia requires less than 1.8 gha of world average space. In the context of tourism, the conclusion is relatively severe for distant destinations, because the footprint for a journey equals or even exceeds the biological capacities required for the activity involved, and this is particularly true of the Seychelles. A necessary condition for development to be sustainable is clearly that the EF must be smaller than the biocapacity available [27].

The question of distance also has a relatively significant impact with regard to the previous observation. The fraction attributable to fossil energy consumption makes up the greatest part of the EF [15], and transportation and accommodation are the main consumptions that involve fossil energy to a substantial extent. Consequently, long-distance travel considerably increases the EF per tourist. According to [5], a linear relation between distance and footprint is proved with a high correlation between these two indicators. In this way, the greater the distance travelled, the heavier the EF. In this context, the heavy footprint of ecotourists travelling to the southern hemisphere appears to be in contradiction to the objective of sustainable development, despite the fact that ecotourism may be sustainable on the local level (in the sense that its puts a minimum threat to local ecosystems through the conversion of lands, collection of species, trampling, etc.). Thus, the problem of air travel is particularly striking with regard to the development of tourism, to the extent that the intensification of international tourism, and therefore the multiplication of air miles linked to tourism, can only increase 
the pressure of tourism on the global environment as a result of the relentlessly increasing emission of greenhouse gasses [58].

The comparison between the two major variables, air travel and length of stay, proves also that length of stay has a marginal impact on the results. For example, if we consider a length of stay of the order of 10 days for both destinations (so twice that of Tunisia), it will of course impact the consumption in the new calculation of the footprint of a tourist in Tunisia with an increase of arable land, pasture, forest and sea space, but not the other elements like built up land and fossil energy land which do not depend on the length of stay or marginally for the energy used for accommodation (approximately less than 5\% of the total footprint).

Our comparison of the data available for Tunisia and for the Seychelles confirms the major impact of air travel in the EF of tourists, which is consistent with the results shown above and extracted from the work of [5] on various tourism scenarios. According to [5], a "mass" tourism destination such as Tunisia is less sustainable than an ecotourism destination as in the Seychelles, and our results prove that also if we just focus on the tourism activity at the national level with the higher number of arrivals for Tunisia. Nevertheless, this conclusion has a sense only at the national level because the individual footprint of a tourist is higher for the Seychelles than for Tunisia (around three times more). In this way, 433,581 international tourists in Tunisia have the same impact on the global scale as 117,690 international tourists travelling to the Seychelles. Thus, it limits the sustainability of ecotourism in destinations like the Seychelles because of the air travel. It proves that tourist travel should involve relatively small distances and the development of tourism should be constrained in order to reduce the global pressure on the environment. In order to become more sustainable, destinations should seek to attract clients from close source markets and regional tourism involving short transport distances may often only be sustainable from an ecological point of view.

Finally, one of the clearest conclusions of the EFA is that "mass" tourism near to the countries of origin of most of the tourists will have a less harmful impact at the global level, than a more sustainable form of tourism, such as ecotourism, that takes place at destinations far from the countries of origin of most of the tourists. This conclusion leads to problems, because most of the major areas of high biodiversity, which are the basis of the growth of ecotourism (biodiversity hotspots), are located in the southern hemisphere [59].

\section{Conclusions}

The sustainability of ecotourism can be called into question if it takes place in southern countries involving long-distance travel. Thus, ecotourism appears to be only a partially sustainable form of consumption, and can be partially responsible for causing ecological damage at the global level, unless it takes place in countries that are relatively close to the countries of origin of the tourists.

Meanwhile, our conclusion must be put into context for at least three reasons.

First, as we have previously underlined, freshwater withdrawals are not taken into account in EF. According to Mekonnen and Hoekstra [60], the WF of the global average consumer in the period 1996-2005 was $1,385 \mathrm{~m}^{3} /$ year The EF discussion should be enriched with a water-use perspective in addition to a use-of-space perspective. The average consumer in Tunisia has a WF of $2,217 \mathrm{~m}^{3} /$ year while the average citizen in the Seychelles has a WF of $2,192 \mathrm{~m}^{3} /$ year. It is quite similar and above the 
overall average. Now tourism, by the pressure it exerts constitutes a major factor of stress on freshwater. To evaluate and compare the effect of the two forms of tourism, WF should be taken into consideration. Such a footprint will be particularly relevant in our case. Indeed, Tunisia is an arid country. Pressure exerted by mass tourism could largely contribute to the scarcity of freshwater resources. If impact is mainly local, side effects could be produced, especially through increasing migratory phenomenon. Seychelles, as an archipelago, must tackle concentration of tourism on coastal areas. Small islands are very vulnerable to the pressure exerted by tourism with access to freshwater and land. A strong tourist pressure could affect significantly access to freshwater for the native population. In the case of Tunisia, as in the case of Seychelles, WF is certainly a relevant indicator for tourism impact and should be used in addition to EF.

Second, EF does not take into account irreversibility effects. From such a point of view mass tourism in Tunisia can be different, to ecotourism in Seychelles. Degradations produced by mass tourism could be, to a certain extent, irreversible, whereas ecotourism effects are probably less irreversible, because they are less concentrated.

Third, EF does not take into account technological changes. Technological changes in travel that reduce their impact could significantly modify our results. As we underlined, our study is static and we do not use EF more than it should be used. The dynamics of sustainability is poorly represented by this indicator. It produces only a static picture, at a given moment of time and our results must be considered in this way: a comparison between two forms of tourism at a given moment of time. It does not signify that ecotourism, if it be developed through cleaner travelling means, would not be more interesting than mass tourism at a global level.

A challenge for future research is to bring EFA, WFA and the other types of sustainability analysis together in one framework. A first step would be to harmonise the footprint calculation methodologies and develop ways to use EF, WF and other sustainability estimates in a complementary way to assess the sustainability of the use of the natural environment by human beings.

\section{Acknowledgements}

We thank anonymous reviewers for helpful comments on an early draft of this paper. The usual disclaimer applies.

\section{References and Notes}

1. Rees, W.E. Ecological footprints and appropriated carrying capacity: What urban economics leaves out. Environ. Urban. 1992, 4, 121-130. 
2. Rees, W.E.; Wackernagel, M. Ecological footprints and appropriated carrying capacity: Measuring the natural capital requirements for the human economy. In Investing in Natural Capital: The Ecological Economics Approach to Sustainability; Jansson, A.M., Hammer, M., Folke, C., Costanz, R., Eds.; Island Press: Washington, DC, USA, 1994; pp. 362-390.

3. Chambers, N.; Simmons, C.; Wackernagel, M. Sharing Nature' Interests: Ecological Footprints as an Indicator of Sustainability; Earthscan: London, UK, 2000.

4. Hoekstra, A.Y. Human appropriation of natural capital: A comparison of ecological footprint and water footprint analysis. Ecol. Econ. 2009, 68, 1963-1974.

5. Hunter, C.; Shaw, J. Applying the ecological footprint to ecotourism scenarios. Environ. Conserv. 2006, 32, 294-304.

6. For detailed descriptions of the procedures involved in EFA see [3,7-9].

7. Monfreda, C.; Wackernagel, M.; Deumling, D. Establishing national natural capital accounts based on detailed ecological footprint and biological capacity assessments. Land Use Policy 2004, 21, 231-246.

8. Wackernagel, M.; Monfreda, C.; Moran, D.; Wermer, P.; Goldfinger, S.; Deumling, D.; Murray, M. National Footprint and Biocapacity Accounts 2005: The Underlying Calculation Method; Global Footprint Network: Oakland, CA, USA, 2005.

9. Wackernagel, M.; Onisto, L.; Bello, P.; Linares, A.C.; Falfan, I.S.L.; Garcia, J.M.; Guerrero, A.I.S. National capital natural accounting with the ecological footprint concept. Ecol. Econ. 1999, 29, 375-390.

10. Ewing, B.; Goldfinger, S.; Wackernagel, M.; Stechbart, M.; Rizk, S.; Reed, A.; Kitzes, J. The Ecological Footprint Atlas 2008; Global Footprint Network: Oakland, CA, USA, 2008.

11. Wackernagel, M.; Yount, J.D. Footprints for sustainability: The next steps. Environ. Dev. Sustain. 2000, pp. 21-42.

12. Hall, C.M. Tourism Planning: Policies, Processes and Relationships; Pearson Education: Upper Saddle River, NJ, USA, 2008.

13. Cooper, C.; Hall, C.M. Contemporary Tourism: An International Approach; Butterworth-Heinemann: Oxford, UK, 2008.

14. Large parts of some coastal areas of Tunisia can be considered as "mass tourism". Tourism is one of the most dynamic sectors of the economy and is a major source of foreign exchange earnings. The tourist arrival figure in 2010 was 6.9 million.

15. Gössling, S.; Borgström-Hansson, C.; Hörstmeier, O.; Saggel, S. Ecological footprint analysis as a tool to assess tourism sustainability. Ecol. Econ. 2002, 43, 199-211.

16. The tourist arrival figure in 2010 was 175,000 .

17. Even if serious doubts have been expressed about the effectiveness of environmental conservation [18].

18. Lindén, O.; Lundin, C.G. The Journey from Arusha to Seychelles. Successes and failures in integrated coastal zone management in Eastern Africa and island states. In Proceedings of the Second Policy Conference on Integrated Coastal Zone Management in Eastern Africa and Island States, Seychelles, 23-25 October 1997.

19. Froger, G. Le tourisme durable dans les Suds : Solution ou mirage? Mondes en Dév. 2012, 157, 1. 
20. Weaver, D.B.; Lawton, L.J. Twenty years on: The state of contemporary ecotourism research. Tour. Manag. 2007, 28, 1168-1179.

21. Wackernagel, M.; Rees, W.E. Our Ecological Footprint: Reducing Human Impact on the Earth; New Society Publishers: Gabriola Island, BC, Canada, 1996.

22. We retain the terminology used by Cooper and Hall [13], even if several updates in the National Footprint Accounts have been released by the Global Footprint Network [10,23]. Indeed, new factors do not include fossil energy land, arable land, pasture and sea space anymore but $\mathrm{CO}_{2}$ uptake-land (or carbon footprint, i.e., forest for carbon sequestration), cropland, grazing land and fishing ground. The factors built-up land and forest (for timber and fuel wood) remain.

23. Ewing, B.; Moore, D.; Goldfinger, S.; Oursler, A.; Reed, A.; Wackernagel, M. The Ecological Footprint Atlas 2010; Global Footprint Network: Oakland, CA, USA, 2010.

24. World Wildlife Fund. Living Planet Report; WWF: Gland, Switzerland, 2000.

25. Wackernagel, M.; Lewan, L.; Borgström Hansson, C. Evaluating the use of natural capital with the ecological footprint: Applications in Sweden and Subregions. Ambio 1999, 28, 604-612.

26. Bossel, H. Indicators for Sustainable Development: Theory, Method, Applications; A Report for the Balaton Group, International institute for Sustainable Development: Winnipeg, MB, Canada, 1999.

27. Hunter, C.; Shaw, J. The ecological footprint as a key indicator of sustainable tourism. Tour. Manag. 2007, 28, 46-57.

28. Gössling, S.; Peters, P.; Scott, D. Consequences of climate policy for international tourist arrivals in developing countries. Third World Q. 2008, 29, 873-901.

29. Gössling, S.; Schumacher, K.P. Implementing carbon neutral destination policies: Issues from the Seychelles. J. Sustain. Tour. 2010, 18, 377-391.

30. Office National du Tourisme Tunisien (ONTT). Le Tourisme Tunisien en Chiffre; ONTT Tunisia, Ministry of Tourism: Tunis, Tunisia, 2004.

31. Gössling, S. Tourism, environmental degradation and economic transition: Interacting processes in a Tanzanian coastal community. Tour. Geogr. 2001, 3, 230-254.

32. This hypothesis is needed to use the same process of calculation as with [15]. Some authors consider that tourists consume more during their stay [33]. Nevertheless, if tourists consume more when they are on holidays in developing countries, this is balanced by the specificities of local products, which have a smaller EF than similar products in developed countries.

33. Cogoy, M. The consumer as a social and environmental actor. Ecol. Econ. 1999, 28, 385-398.

34. According to [35], in 2009, the EF obtained for the Tunisian case is of the order of 0.5225 gha and the aggregated footprint is of the order of 2,046,092 (for data see Appendix 1, 2 and 3). The difference is not significant between 2004 and 2009 for the individual footprint because of the similar repartition of category of accommodation establishments and the similar repartition of nationality of tourists. The aggregated footprint is higher for 2009 because of the increase of tourist arrivals.

35. Office National du Tourisme Tunisien (ONTT). Le Tourisme Tunisien en Chiffre; ONTT Tunisia, Ministry of Tourism: Tunis, Tunisia, 2009.

36. Kitzes, J.; Peller, A.; Goldfinger, S.; Wackernagel, M. Current methods for calculating national ecological footprint accounts. Sci. Environ. Sustain. Soc. 2007, 4, 1-9. 
37. Van den Bergh, J.; Verbruggen, H. Spatial sustainability, trade and indicators: An evaluation of the ecological footprint. Ecol. Econ. 1999, 29, 61-72.

38. Moffatt, I. Sustainable Development: Principles, Analysis and Policies; Parthenon Press: Carnforth, UK, 1996.

39. Lange, G.M. How to make progress toward integrating biophysical and economic assessments. Ecol. Econ. 1999, 29, 29-32.

40. Goldfinger, S.; Wackernagel, M.; Niazi, S.; Peller, A.; Kaercher, M.; Kitzes, J.; Ewing, B.; Silvestri, F.; Hayes, K.; Wakabayashi, T. Africa-Ecological Footprint and Human Well-Being; WWF, Global Footprint Network, SDC: Oakland, CA, USA, 2008.

41. David, M.; Dormoy, C.; Haye, E.; Tregouët, B. Une expertise de l'empreinte écologique; Etudes et documents No. 16 ; Commissariat général du développement durable: Paris, France, 2010.

42. "The EF includes only those aspects of resource consumption and waste production for which the Earth has regenerative capacity, and where data exist that allow this demand be expressed in terms of productive area. For example, freshwater withdrawals are not included in the footprint, although the energy used to put or treat the water is" [40] (p. 28). The EF does not, and is not intended to measure freshwater flows.

43. Hoekstra, A.Y. Virtual water trade. In Proceedings of the International Expert Meeting on Virtual Water Trade, Delft, The Netherlands, 12-13 December 2002.

44. The WF of an individual or community is defined as the total volume of freshwater that is used to produce the goods and services consumed by the individual or community. Though they are often compared and contrasted, EF and WF are, as indicators, fundamentally incapable of being substituted. Whereas the EF denotes the bioproductive area (global hectares) needed to sustain a population (or measures the biological capacity a population uses), the WF represents the freshwater volume (cubic meters per year) required. They each provide a different piece of information in the sustainability puzzle. Instead of being seen as competing metrics, they should be seen as two complementary indicators of natural capital use in relation to human consumption. For more information on the methodology and the applications of WF, see [4] and [45].

45. Hoekstra, A.Y.; Chapagain, A.K.; Aldaya, M.M.; Mekonnen, M.M. The Water Footprint Assesment Manual_-Setting the Global Standard; Earthscan: London, UK, 2011.

46. Two differences are, for example, that EF are usually calculated based on global average productivities, while WF are calculated based on local productivities, and that EF are often not made spatially explicit, while WF are [4]. Furthermore, the components of an EF are weighted (based on equivalence factors) before adding up to the total EF, while the components of a WF are added without weighting. For more information on the similarities and differences between EF and WF analysis, see [4].

47. World Wildlife Fund. Living Planet Report; WWF: Glan, Switzerland, 2008.

48. Moffatt, I. Ecological footprint and sustainable development. Ecol. Econ. 2000, 32, 359-362.

49. Bossel, H. Indicators for Sustainable Development: Theory, Method, Applications; A Report for the Balaton Group; International institute for Sustainable Development: Winnipeg, MB, Canada, 1999.

50. Hass, J.L.; Brunvoll, F.; Hoie, H. Overview of Sustainable Development Indicators used by National and International Agencies; OECD Statistics Working papers; OECD Publishing: Paris, France, February 2002. 
51. Ceron, J.-P.; Dubois, G. Tourims and sustainable development indicators: The gap between theoretical demands and practical achievements. Curr. Issue Tour. 2003, 6, 54-75.

52. Reddy, M.V. Sustainable tourism rapid indicators for less developed islands: An economic perspective. Int. J. Tour. Res. 2008, 10, 557-576.

53. Bojanic, D. Using a tourism importance-performance typology to investigate environmental sustainability on a global level. J. Sustain. Tour. 2011, 19, 989-1003.

54. Manning, E.W.; Clifford, G.; Dougherty, D.; Ernst, M. What Managers Need to Know-A Practical Guide to the Development and Use of Indicators of Sustainable Tourism; World Tourism organization: Madrid, Spain, 1996.

55. Wiedmann, T.; Minx, J. A Definition of Carbon Footprint; ISAUK Research Report 2007-01; Durhau, Centre for integrated Sustainability Analysis, ISAUK Research \& Consulting: Durham, UK, 2007.

56. Weidema, B.P.; Thrane, M.; Christensen, P.; Schmidt, J.; Løkke, S. Carbon footprint. A catalyst for life cycle assessment. J. Ind. Ecol. 2008, 12, 3-6.

57. Ledant, J.-P. L'empreinte Ecologique: Un Indicateur de...Quoi? Working paper IDD/J-P.L; Institut Pour le Développement Durable: Ottignies, Belgium, 30 December 2005.

58. Scott, D.; Becken, S. Adapting to climate change and climate policy: Progress, problems and potentials. J. Sustain. Tour. 2010, 18, 283-295.

59. Christ, C.; Hillel, O.; Matus, S.; Sweeting, J. Tourism and Biodiversity, Mapping Tourism's Global Footprint; UNEP: Nairobi, Kenya, 2003.

60. Mekonnen, M.M.; Hoekstra, A.Y. National water Footprint Accounts: The Green, Blue and Grey Water Footprint of Production and Consumption; Value of Water Research Report Series No. 50; UNESCO-IHE: Delft, The Netherlands, 2011.

\section{Appendix}

Appendix 1: Tourist arrivals in Tunisia. These figures relate to arrivals by air according to $[1,2]$.

\begin{tabular}{lccc}
\hline \multicolumn{1}{c}{ Country } & Arrivals 2004 & Arrivals 2009 & km \\
\hline France & 986,669 & $1,344,697$ & 2,575 \\
Germany & 561,324 & 484,154 & 3,541 \\
Italy & 425,026 & 383,851 & 1,931 \\
England & 299,410 & 275,652 & 3,862 \\
Belgium & 139,140 & 168,108 & 3,380 \\
Czech & 128,189 & 92,713 & 3,058 \\
Spain & 113,025 & 90,230 & 2,414 \\
Russia & 99,021 & 126,516 & 5,955 \\
Switzerland & 96,276 & 99,822 & 2,414 \\
Austria & 82,770 & 60,654 & 2,736 \\
Scandinavian countries & 80,128 & 104,617 & 4,345 \\
Other west European countries & 140,529 & 154,698 & 3,219 \\
Other east European countries & 238,529 & 357,791 & 4,023 \\
Other world countries & 160,991 & 172,197 & 8,047 \\
\hline
\end{tabular}


Appendix 2. Area of the airports. According to [3].

\begin{tabular}{l|lllllll}
\hline Airports & Tunis & Monastir & Tabarka & Sfax & Gafsa & Tozeur & Djerba \\
Area (ha) & 820 & 200 & 240 & 327 & 235 & 690 & 295 \\
\hline
\end{tabular}

Appendix 3. Capacity. According to $[1,2]$.

\begin{tabular}{ccc}
\hline Category & Capacity 2004 & Capacity 2009 \\
\hline$*$ & 2,987 & 5,300 \\
$* *$ & 21,771 & 22,600 \\
$* * *$ & 78,149 & 85,400 \\
$* * * *$ & 74,774 & 77,100 \\
$* * * * *$ & 25,724 & 28,700 \\
$\mathrm{NC}$ & 10,745 & 9,600 \\
\hline
\end{tabular}

\section{References}

1. Office National du Tourisme Tunisien (ONTT). Le Tourisme Tunisien en Chiffre; ONTT Tunisia, Ministry of Tourism: Tunis, Tunisia, 2004.

2. Office National du Tourisme Tunisien (ONTT). Le Tourisme Tunisien en Chiffre; ONTT Tunisia, Ministry of Tourism: Tunis, Tunisia, 2009.

3. Office de l'Aviation Civile et des Aéroports (OACA). Airports Identity Card; OACA Tunisia: Ministry of Transport: Tunis, Tunisia, 2006. Available online: http://www.oaca.nat.tn (accessed on 19 December 2010).

(C) 2012 by the authors; licensee MDPI, Basel, Switzerland. This article is an open access article distributed under the terms and conditions of the Creative Commons Attribution license (http://creativecommons.org/licenses/by/3.0/). 